\title{
Peripheral nervous system defects in $e r b B 2$ mutants following genetic rescue of heart development
}

\author{
Masresha T. Woldeyesus, ${ }^{1}$ Stefan Britsch, ${ }^{1}$ Dieter Riethmacher, ${ }^{1,4}$ Lan $\mathrm{Xu}{ }^{2}$, \\ Eva Sonnenberg-Riethmacher, ${ }^{1,4}$ Faikah Abou-Rebyeh, ${ }^{1}$ Richard Harvey, ${ }^{3}$ Pico Caroni, ${ }^{2}$ \\ and Carmen Birchmeier ${ }^{1,5}$

\begin{abstract}
${ }^{1}$ Max-Delbrück-Center for Molecular Medicine, 13092 Berlin, Germany; ${ }^{2}$ Friedrich Miescher Institut, 4058 Basel, Switzerland; ${ }^{3}$ The Victor Chang Cardiac Research Institute, Darlinghurst 2010, Australia
\end{abstract}

The ErbB2 tyrosine kinase functions as coreceptor for the neuregulin receptors ErbB3 and ErbB4 and can participate in signaling of EGF receptor (ErbB1), interleukin receptor gp130, and G-protein coupled receptors. $E r b B 2^{-/-}$mice die at midgestation because of heart malformation. Here, we report a genetic rescue of their heart development by myocardial expression of erbB2 cDNA that allows survival of the mutants to birth. In rescued $e r b B 2$ mutants, Schwann cells are lacking. Motoneurons form and can project to muscle, but nerves are poorly fasciculated and disorganized. Neuromuscular junctions form, as reflected in clustering of AChR and postsynaptic expression of the genes encoding the $\alpha$-AChR, AChE, $\epsilon$-AChR, and the RI subunit of the cAMP protein kinase. However, a severe loss of motoneurons on cervical and lumbar, but not on thoracic levels occurs. Our results define the roles of Schwann cells during motoneuron and synapse development, and reveal different survival requirements for distinct motoneuron populations.

[Key Words: Motoneuron loss; neuromuscular synapse; coreceptor; neuregulin; AChR]

Received May 17, 1999; revised version accepted August 18, 1999.

The erbB2 (c-neu, HER2) gene encodes one of the four members of the mammalian ErbB family of receptor tyrosine kinases (Weiss et al. 1997; Tzahar and Yarden 1998). ErbB2 has oncogenic potential when mutated or overexpressed, and is frequently amplified and/or overexpressed in human carcinomas. Despite an intensive search, no high-affinity ligand has been identified for ErbB2. Biochemical analyses indicate that ErbB2 acts as a coreceptor for ErbB3 and ErbB4 (Goldman et al. 1990; Carraway and Cantley 1994) and ErbB1 (the EGF receptor). ErbB2 has been implicated in signaling of interleukins, and forms complexes with the gp130 subunit of the IL-6 receptor (Qiu et al. 1998). Moreover, ErbB2 is transactivated on signaling of G-protein-coupled receptors (Daub et al. 1996). Genetic evidence shows that ErbB2 participates in the transmission of signals given by neuregulin-1 (Burden and Yarden 1997). From the single neuregulin-1 gene, many different isoforms of the factor are produced by the usage of different promoters and by alternative splicing. These isoforms bind ErbB4 and/or ErbB3, and were characterized independently as (1) a factor able to induce tyrosine phosphorylation of the ErbB2

\footnotetext{
${ }^{4}$ Present address: Zentrum für Molekulare Neurobiologie, 20251 Hamburg, Germany.

${ }^{5}$ Corresponding author.

E-MAIL cbirch@mdc-berlin.de; FAX +49-30-9406 3765.
}

receptor as well as growth and differentiation of epithelial cells (NDF or heregulin; Holmes et al. 1992; Wen et al. 1992); (2) a mitogen for Schwann cells (glial growth factor; Marchionni et al. 1993); and (3) an inducer of acetylcholine receptor (AChR) expression in cultured myoblasts (AChR inducing activity, ARIA; Falls et al. 1993).

The ErbB3 receptor resembles other receptors of the ErbB family in general structure (Kraus et al. 1989; Plowman et al. 1990). However, the sequence of the ErbB3 tyrosine kinase domain diverges from the consensus tyrosine kinase sequence, and ErbB3 has no or only very low tyrosine kinase activity, even in the presence of its high-affinity ligand neuregulin-1. However, when coexpressed with the EGF receptor, ErbB2 or ErbB4, tyrosine phosphorylation of ErbB3 is observed in response to ligands like EGF or neuregulin-1 (Lenferink et al. 1998; Pinkas et al. 1998; Riese and Stern 1998). Biochemical evidence thus shows that various receptors of the ErbB family can function as coreceptors for ErbB3, which appear to provide in trans the tyrosine kinase activity necessary for ErbB3 signaling. Tyrosine phosphorylation of ErbB3 results in the generation of docking sites for substrates like PI-3-kinase (Tzahar and Yarden 1998).

Mice with erbB2 null mutations die before E11 (Lee et al. 1995). Analysis of these animals showed that ErbB2 is required for heart morphogenesis and the development of neural crest cells and their derivatives (Lee et al. 1995; 
Erickson et al. 1997; Britsch et al. 1998). In such mice, a marked reduction of Schwann cell precursors that accompany the spinal nerves is observed at E10.5, and cranial sensory and sympathetic ganglia are severely hypoplastic. The phenotypes in neural crest cell derivatives are similar in erbB3, erbB2, and neuregulin-1 mutant mice at this stage, indicating that ErbB2/ErbB3 heterodimers transmit the neuregulin-1 signal in neural crest cells (Lee et al. 1995; Meyer and Birchmeier 1995; Erickson et al. 1997; Riethmacher et al. 1997; Britsch et al. 1998). In contrast, erbB4, erbB2, and neuregulin-1 mutant mice display similar phenotypes in the heart ventricles, indicating that ErbB2/ErbB4 heterodimers transmit the neuregulin-1 signal in the myocardium (Gassmann et al. 1995; Lee et al. 1995; Meyer and Birchmeier 1995; Erickson et al. 1997).

The functional analysis of ErbB2 was limited, as mice with erbB2 null mutations die at midgestation (Lee et al. 1995; Erickson et al. 1997; Britsch et al. 1998). We rescued the mutant embryos by the expression of erbB2 cDNA under the control of the heart-specific $N k x 2.5$ promoter. This enabled us to analyze erbB2 function during late developmental stages.

We demonstrate that in rescued erbB2 mutant mice, neuromuscular junctions form, as reflected in clustering of AChR and postsynaptic expression of the genes encoding the $\alpha-A C h R, A C h E, \epsilon-A C h R$, and the RI subunit of the cAMP protein kinase. Thus, synapse formation and maturation take place, despite the absence of Schwann cells observed in these animals and despite the lack of ErbB2 receptor in the muscle. However, a severe loss of motoneurons on cervical and lumbar, but not on thoracic levels, occurs. Our results define the roles of Schwann cells during motoneuron and synapse development, and reveal different survival requirements for distinct motoneuron populations.

\section{Results}

Generation of the $\mathrm{Nkx} 2.5^{\mathrm{erbB} 2}$ allele

The lethality of erbB2 $2^{-/-}$mice at E11 was attributed to myocardial malformation (Lee et al. 1995; Erickson et al. 1997; Britsch et al. 1998). To rescue the erbB2 mutants, we expressed erbB2 cDNA under the control of the $N k x 2.5$ gene, which is expressed specifically in the myocardium (Lints et al. 1993). Rat erbB2 cDNA was inserted into exon 1 of $N k x 2.5$ by homologous recombination in ES cells (Fig. 1A,B), and mutant ES cells were used to generate mice that express the erbB2 cDNA under the control of the Nkx2.5 promoter. Animals with one copy of the $N k x 2.5^{\text {erbB2 }}$ allele did not display an overt phenotype and were fertile. However, erbB2 ${ }^{-/-}$embryos that carry in addition one $N k x 2.5^{\text {erbB2 }}$ allele survived beyond E11 (Table 1). At E10.5, the expected Mendelian ratio of rescued erbB2-/- was observed. Some rescued erbB2 ${ }^{-/-}$ embryos were lost between E12.5 and E14.5. At E14.5 and E18.5, their frequency corresponded to $5 \%-6 \%$ (Table 1). A similar reduced survival was observed previously for erbB3-/- embryos (Riethmacher et al. 1997).
At birth, rescued erbB2 mutant animals displayed an overall size reduction, they were cyanotic, did not breathe or move spontaneously, and their lung alveoli did not expand, although the heart continued to beat for some time.

We found that the $N k x 2.5^{\text {erbB2 }}$ allele rescues trabeculation of the heart ventricle of erbB2 mutants at E10.5 (Fig. 1D). Compared with control animals, the extent of trabeculation is moderately reduced (Fig. 1D, cf. a and b). At E18.5, the heart of rescued erbB2 mutant embryos is well developed, although it is smaller by $\sim 30 \%$, which corresponds to the reduced size of the entire animal. RTPCR analysis demonstrated that transcripts derived from the $N k x 2.5^{\text {erbB2 }}$ allele are present in the heart, but not in skeletal muscle or in brain of rescued erbB2 mutant embryos (Fig. 1C). Thus, expression of erbB2 cDNA under the control of the $N k x 2.5$ promoter rescues heart development in erbB2 ${ }^{-/-}$mice and can allow survival of the mutants to birth.

Essential functions of erbB2 in development of Schwann cells and other neural crest cell derivatives

Rescued erbB2 mutant embryos, like erbB3 mutant embryos, displayed defects in the development of Schwann cells and other neural crest cell derivatives. At early stages (E10.5, E12.5), severe reductions in the numbers of Schwann cell precursors were observed in the roots of spinal nerves. Sox10 or $\mathrm{P}_{0}$-positive Schwann cell precursors are lacking in distal portions of peripheral nerves, that is, along cutaneous and intercostal nerves at E12.5 or E15.5 (Fig. 2, cf. b and c and e and $\mathrm{f}$ with controls in a and $d$, respectively). Semithin sections through the nerves of the brachial plexus of rescued erbB2 and in erbB3 mutant embryos at E15.5 demonstrate a reduced nerve diameter (Fig. 2, compare h and i with control in g); nuclei within the nerve are rare (arrowhead in Fig. 2i). A histologically defined layer of cells that surround nerves was observed (arrows in Fig. 2h,i; cf. control in g), whose identity is unclear as these cells neither express Sox10, $P_{o}$, nor Patched (not shown). Immunohistology indicated that S100-positive cells were not detected at synapses or in distal projections in thoracic muscle at E15.5 or E18.5 (Fig. 5, below, cf. $\mathrm{k}$ and 1 with control in j). However, at E18.5, we observed cells associated with large nerve bundles that display a weak S100-staining (not shown).

Dorsal root ganglia formed in rescued erbB2 mutants and contained a normal number of cells at E12.5 (Fig. 3c). Staining of E12.5 embryos with anti-L1 antibodies indicates that the overall trajectories of cutaneous sensory nerves are not severely altered and that these nerves project to the skin in rescued erbB2 mutants (Fig. 3b). However, sensory cutaneous nerves are severely defasciculated when compared with control embryos (Fig. 3, cf. b with control in a). The appearance of sensory cutaneous nerves is similar in erbB3 mutants (not shown). At E14.5 and at later stages, a severe loss of sensory neurons in dorsal root ganglia was observed on all axial levels (Fig. $3 c)$. This is similar to the loss of sensory neurons ob- 
Figure 1. Generation of the $N k \times 2.5^{\text {erbB2 }}$ allele and its effect on heart development in erbB2 mutant mice. $(A)$ The targeting vector (top) contains $N k \times 2.5$ genomic DNA (black), rat erbB2 cDNA (yellow) fused to the ATG in exon 1 of the Nkx2.5 gene, SV40 splice acceptor and donor sites (green), as well as the neomycin resistance $(n e o)$ and thymidine kinase $(t k)$ genes. The Nkx2.5 gene (middle) and the targeted Nkx2.5 locus (bottom) are depicted schematically. Exon sequences are indicated as black boxes. The probe used for Southern hybridization and the predicted fragments obtained after HindIII $(\mathrm{H})$ and $N c o \mathrm{I}(\mathrm{N})$ digestion of genomic DNA are indicated; the predicted size of the fragments from wild-type and Nkx2.5 $5^{\text {erbB2 }}$ alleles correspond to 6 and $8 \mathrm{~kb}$, respectively. (B) Southern blot analysis of genomic DNA from ES cells after digestion

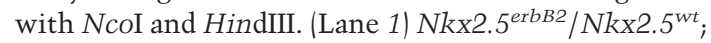
(lane 2) wild type. (C) Analysis of rat erbB2 transcripts that derive from the Nkx2. $5^{\text {erbB2 }}$ locus. (Lane 1) RTPCR was performed on total RNA derived from heart; (lane 2) intercostal and diaphragm muscle; (lane 3) muscle from fore- and hind limbs; (lane 4 ) brain; and (lane 5) a negative control without added RNA. (M) Marker. $(D)$ Histological analysis of the heart from embryos at E10.5 $(a-c)$ and at E18.5 $(d, e)$. The genotypes of the animals are indicated; arrowheads point toward trabecules in wild-type and rescued erbB2 mutants. Bars, top row, $200 \mu \mathrm{m}$; bottom row, $800 \mu \mathrm{m}$.
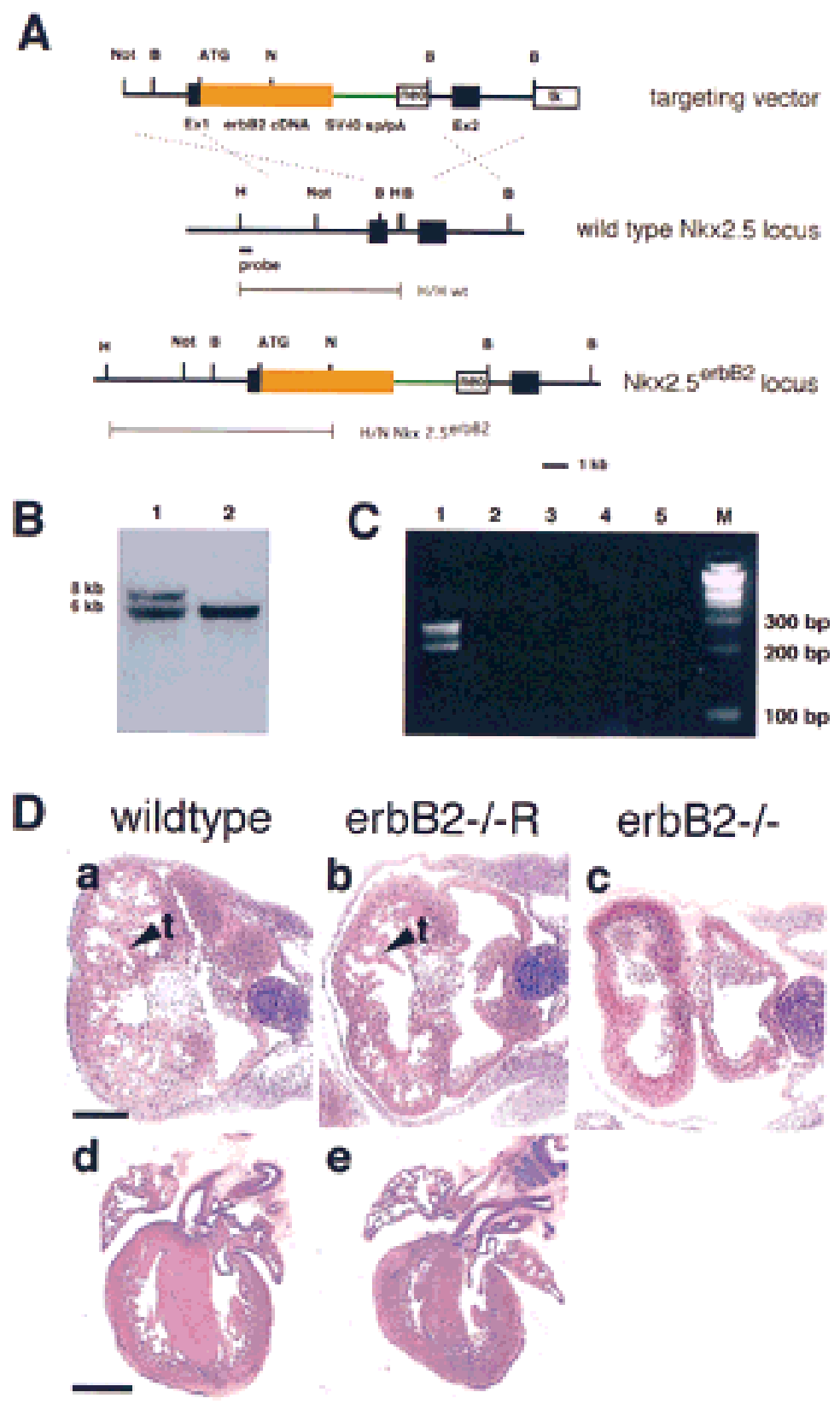

lumbar levels. Rescued erbB2 and erbB3 mutants displayed already moderate reductions in motoneuron numbers in cervical segments when compared with control embryos at this stage (Fig. 4c). In contrast, at E18.5, large proportions of motoneurons were lost on cervical and lumbar levels, whereas motoneurons in thoracic segments were minimally affected (Fig. 4d). Thus, motoneurons form, but subsequently degenerate on cervical and lumbar axial levels.

Nerve morphology and neuromuscular synapse formation in rescued erbB2 mutant embryos

Immunohistology with anti-L1 or anti-GAP43 antibodies revealed an abnormal morphology of nerve projec- 
Table 1. Viability of rescued erbB2 mutant embryos

\begin{tabular}{|c|c|c|c|c|c|c|c|c|c|c|c|c|c|c|}
\hline \multirow{3}{*}{$\begin{array}{l}\text { Genotype of } \\
\text { parents } \\
\text { Genotype of } \\
\text { litter }\end{array}$} & \multicolumn{14}{|c|}{$N k \times 2.5^{\text {erbB2}} /+; \operatorname{erbB2} 2^{+/-} \times N k x 2.5^{+/+} ; \operatorname{erbB} 2^{+/-}$} \\
\hline & \multicolumn{6}{|c|}{$N k \times 2.5^{\text {erbB2}} /+$} & \multicolumn{6}{|c|}{$N k \times 2.5^{+/+}$} & & \\
\hline & \multicolumn{2}{|c|}{$e r b B 2^{+/+}$} & \multicolumn{2}{|c|}{$\operatorname{erbB2} 2^{+/-}$} & \multicolumn{2}{|c|}{$e r b B 2^{-1-}$} & \multicolumn{2}{|c|}{$\operatorname{erbB2} 2^{+/+}$} & \multicolumn{2}{|c|}{$e r b B 2^{+/-}$} & \multicolumn{2}{|c|}{$\operatorname{erbB2^{-/-}}$} & & \\
\hline Expected ratio & & $12.5 \%$ & & $25 \%$ & & $12.5 \%$ & & $12.5 \%$ & & $25 \%$ & & $12.5 \%$ & & \\
\hline E10.5 & 3 & $10 \%$ & 8 & $27 \%$ & 4 & $13 \%$ & 4 & $13 \%$ & 8 & $27 \%$ & 3 & $10 \%$ & $\Sigma$ & 30 \\
\hline E12.5 & 12 & $16 \%$ & 18 & $25 \%$ & 9 & $12 \%$ & 8 & $11 \%$ & 26 & $36 \%$ & 0 & $0 \%$ & $\Sigma$ & 73 \\
\hline E14.5 & 15 & $18 \%$ & 26 & $31 \%$ & 4 & $5 \%$ & 13 & $15 \%$ & 27 & $32 \%$ & 0 & $0 \%$ & $\Sigma$ & 85 \\
\hline E15.5 & 26 & $16 \%$ & 48 & $29 \%$ & 8 & $5 \%$ & 28 & $17 \%$ & 56 & $34 \%$ & 0 & $0 \%$ & $\Sigma$ & 166 \\
\hline E16.5 & 21 & $17 \%$ & 39 & $32 \%$ & 9 & $7 \%$ & 20 & $16 \%$ & 33 & $27 \%$ & 0 & $0 \%$ & $\Sigma$ & 122 \\
\hline E18.5 & 21 & $18 \%$ & 37 & $32 \%$ & 7 & $6 \%$ & 17 & $15 \%$ & 33 & $29 \%$ & 0 & $0 \%$ & $\Sigma$ & 115 \\
\hline
\end{tabular}

Analysis of genotypes of live embryos generated from intercrosses of animals that carry wild-type and mutant $e r b B 2$ and $N k x 2.5^{e r b B 2}$ alleles. The expected Mendelian ratio (expected ratio) for the different genotypes is indicated, and the numbers and percentages of observed live embryos at different developmental stages are shown. Genotypes were identified by PCR analysis on DNA isolated from the yolk sac. In addition to live embryos, embryos without heartbeat or with signs of resorption were observed.

tions and nerve terminals in mutant embryos. We concentrated our analysis on motor nerves originating from thoracic segments of the spinal cord, which are only minimally affected by motoneuron loss in the mutants. In wild-type E15.5 embryos, single bundles of intercostal nerves are observed from which side branches project to

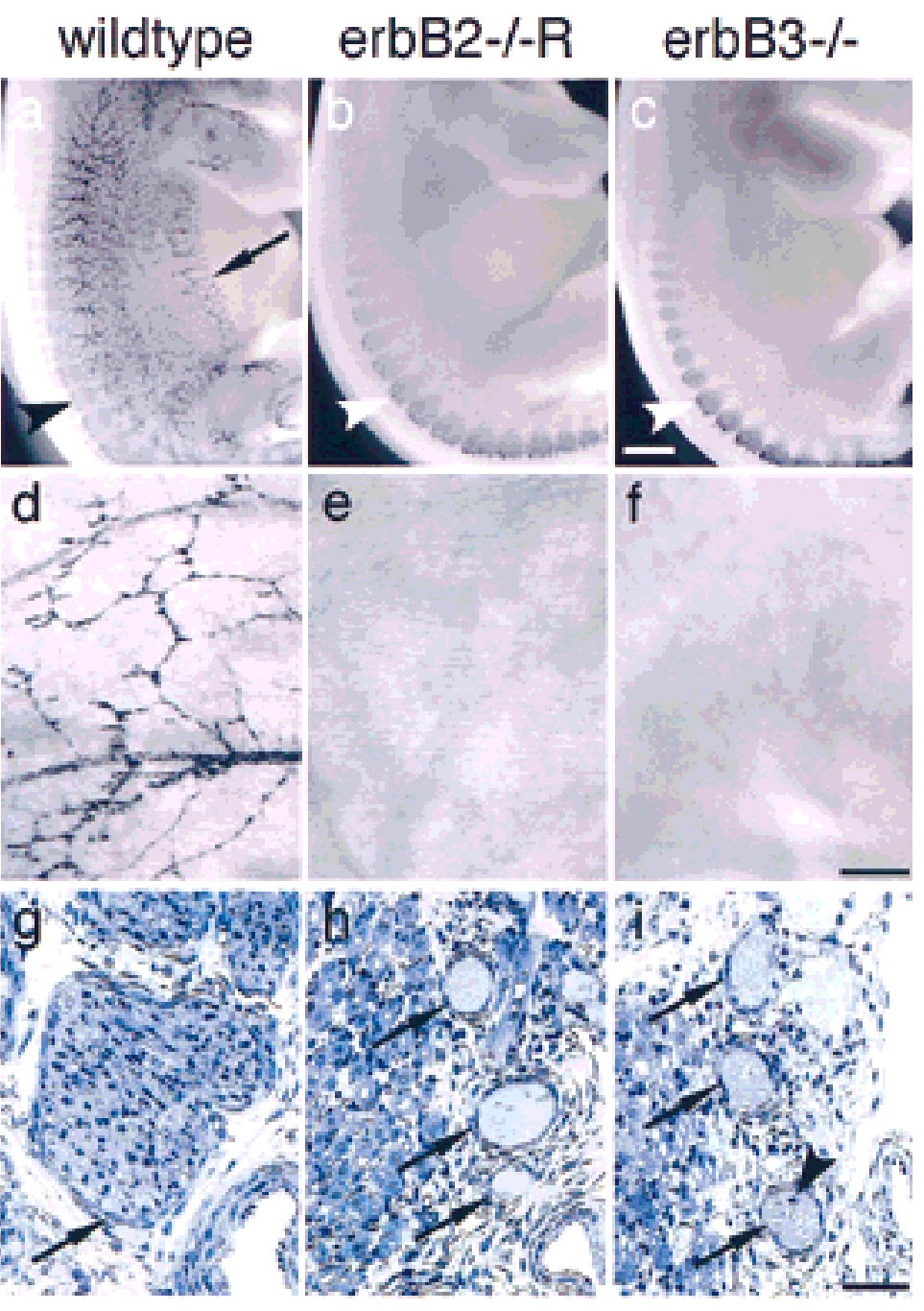

Figure 2. Lack of Schwann cells in rescued erbB2 mutant and in erbB3 mutant embryos. $(a-c)$ Whole-mount in situ hybridization of control $(a)$, rescued $\operatorname{erbB2}(b)$, and erbB3 mutant embryos at E12.5 with a Sox10-specific probe. Sox10-positive Schwann cell precursors observed along the cutaneous sensory nerves in controls (arrow) are absent in the mutants; Sox10-positive cells are present in dorsal root ganglia of control and mutant embryos (arrowheads). Whole-mount in situ hybridization of E15.5 thoraco-abdominal walls from control $(d)$, rescued erbB2 mutant $(e)$, and erbB3 mutant $(f)$ embryos with Sox10 as a probe; Sox10-positive Schwann cell precursors are observed that accompany thoracic nerves in the control, but are absent in the mutants. $(g, h)$ Semithin sections through nerves of the brachial plexus of control $(g)$, rescued erbB2 (h), and erbB3 (i) mutant embryos. Arrows point toward histologically well-defined cellular layers that surround nerves in mice of all genotypes. The arrowhead in $f$ points toward a nucleus in the nerve of a mutant; these are only rarely observed. Bars, $(a-c) 0.5$ $\mathrm{mm} ;(d-f) 0.1 \mathrm{~mm}$; $(g-i) 50 \mu \mathrm{m}$. 

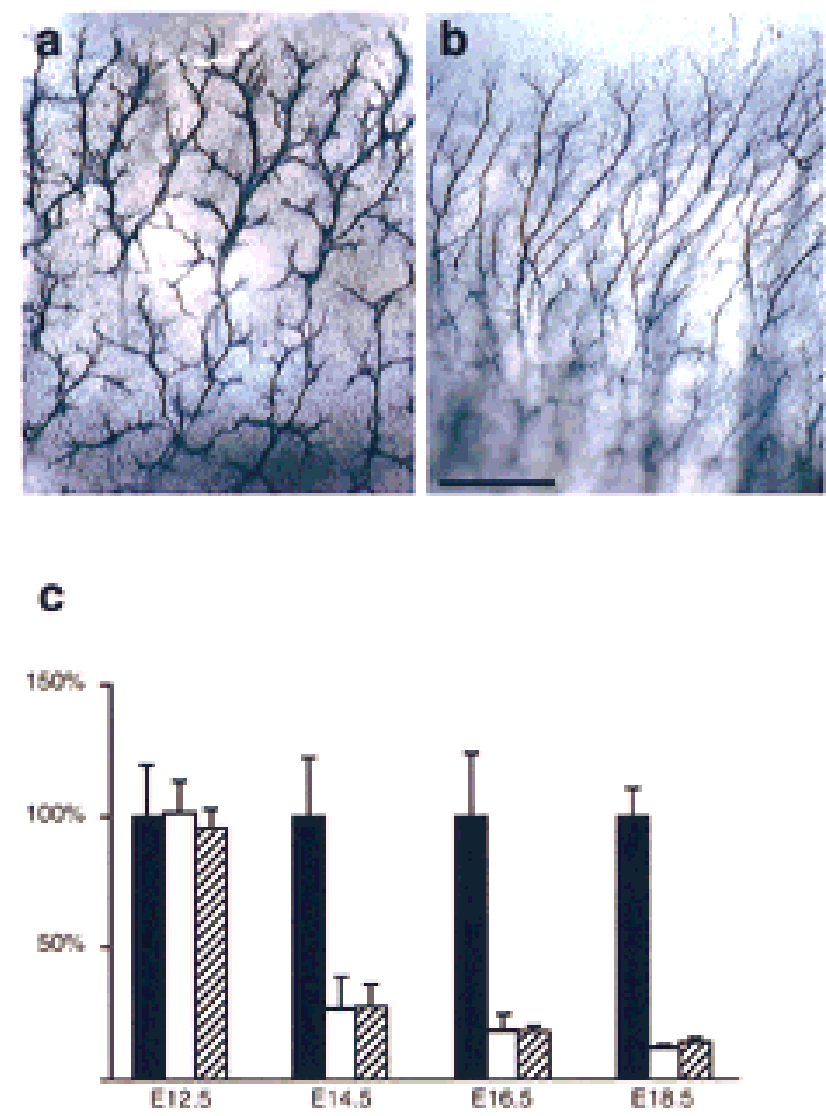

Figure 3. Morphological appearance of sensory cutaneous nerves and loss of sensory neurons in rescued erbB2 mutants and in erbB3 mutants. Sensory cutaneous nerves in the thoracic body wall of control $(a)$ and rescued erbB2 $(b)$ mutant embryos at E12.5 were visualized by whole-mount immunohistochemistry with anti-L1 antibodies. (c) Cell numbers in dorsal root ganglia on E12.5 and neuron numbers on E14.5, E16.5, and E18.5 in control (solid bars), rescued erbB2 mutants (open bars), and erbB3 mutants (hatched bars). The sum of the numbers of cells/ neurons in L4 and L5 dorsal root ganglia were determined; wildtype numbers at each stage were normalized to $100 \%$, and the numbers determined in mutant embryos are displayed as the percentage of the wild-type numbers. Mean percentages \pm S.D. are indicated ( $n=2-4$ embryos in each group).

synaptic areas at regular intervals (Fig.5a). In rescued erbB2 mutants, and in erbB3 mutants at this stage, intercostal nerves are split into several bundles that run in parallel, and side branches are poorly fasciculated and disorganized (Fig. 5b,c). The morphology of intercostal nerves in mutant embryos is similar at E18.5. The phrenic nerve in the diaphragm of rescued erbB2 and of erbB3 mutants at E14.5 is thin and defasciculated. At E15.5, the phrenic nerve in the diaphragm is frequently fragmented and, at later stages, only remnants of the nerve are detectable. This coincides with the loss of motoneurons on cervical levels from which the phrenic nerve originates. In addition, the diaphragm muscle is notably thinned at E18.5 (not shown).

Restoration of erbB2 expression in the heart allowed us to study the potential role of ErbB2 in neuromuscular synaptogenesis. Neuromuscular synapses were visualized by staining with rhodamine-labeled $\alpha$-bungarotoxin, which revealed that AChR clusters are formed and persist in thoracic muscle of rescued erbB2 mutants and of erbB3 mutants. At E18.5, a general disorganization of the nerves was observed that appear defasciculated (Fig. 5di). Frequently, AChR clusters were detected at multiple sites along single nerve bundles in mutants (arrowheads in Fig. 5h,il, and the clusters were often enlarged and nonhomogeneously stained (arrows). In addition, ectopic AChR clusters that were not contacted by nerves were detected in both mutants (not shown). At E15.5, the distribution of AChR clusters was similar in intercostal muscle of rescued erbB2 mutants and of erbB3 mutants. Ultrastructural analysis of synapses in intercostal muscle of rescued erbB2 mutants at E15.5 revealed close nerve-muscle contacts; however, terminal Schwann cells were absent (Fig. 6). Synaptic vesicle accumulations (arrowheads in Fig. 6) and putative pre- and postsynaptic densities were observed. In the wild type, nerve-muscle contact sites were restricted to synaptic profiles, whereas contact regions extending over several tens of microns were detected in the mutant (Fig. 6). The general morphology of nerve and synapses is similar in erbB3 mutants but, compared with rescued erbB2 mutants, the disorganization appears more pronounced (not shown). Clustered AChR are also observed in the diaphragm at
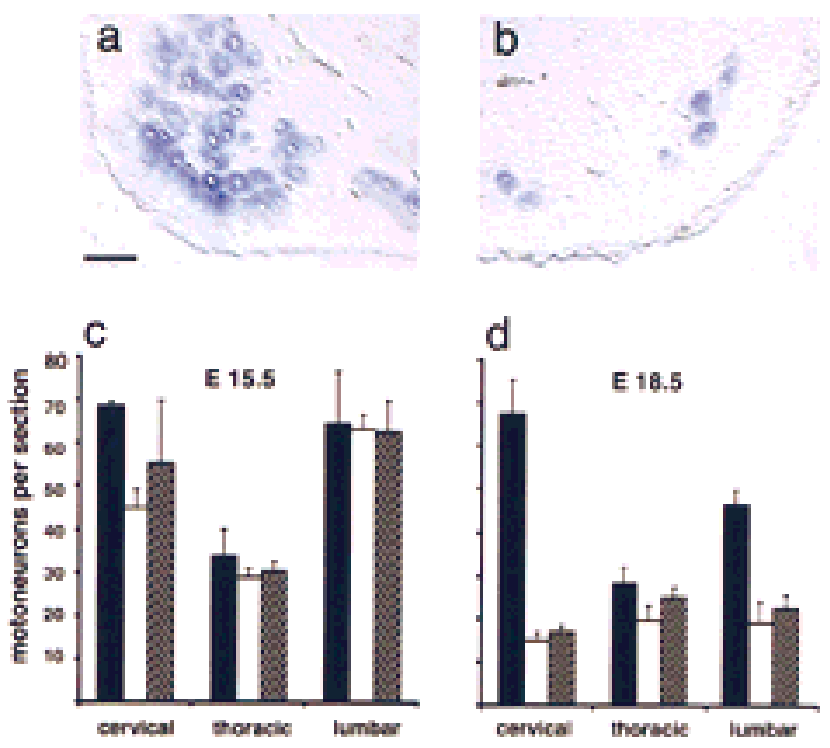

Figure 4. Loss of motoneurons on different axial levels in rescued erbB2 mutants and in erbB3 mutants. Sections from the cervical spinal cord of wild-type $(a)$ and rescued erbB2 mutant (b) animals at E18.5 after in situ hybridization with VAChTspecific probes. $(c, d)$ Motoneuron numbers in cervical, thoracic, and lumbar spinal cord segments obtained from control (solid bars), rescued erbB2 mutants (open bars), and erbB3 mutants. (hatched bars) at E15.5 (c) and E18.5 (d). Mean numbers of motoneurons per section \pm S.D. $(n=2-4$ embryos in each group) are shown. Counts of neurons were not corrected for neuron size, and therefore the numbers of neurons determined at different developmental stages are not strictly comparable. Bar $(a, b)$, $50 \mu \mathrm{m}$. 


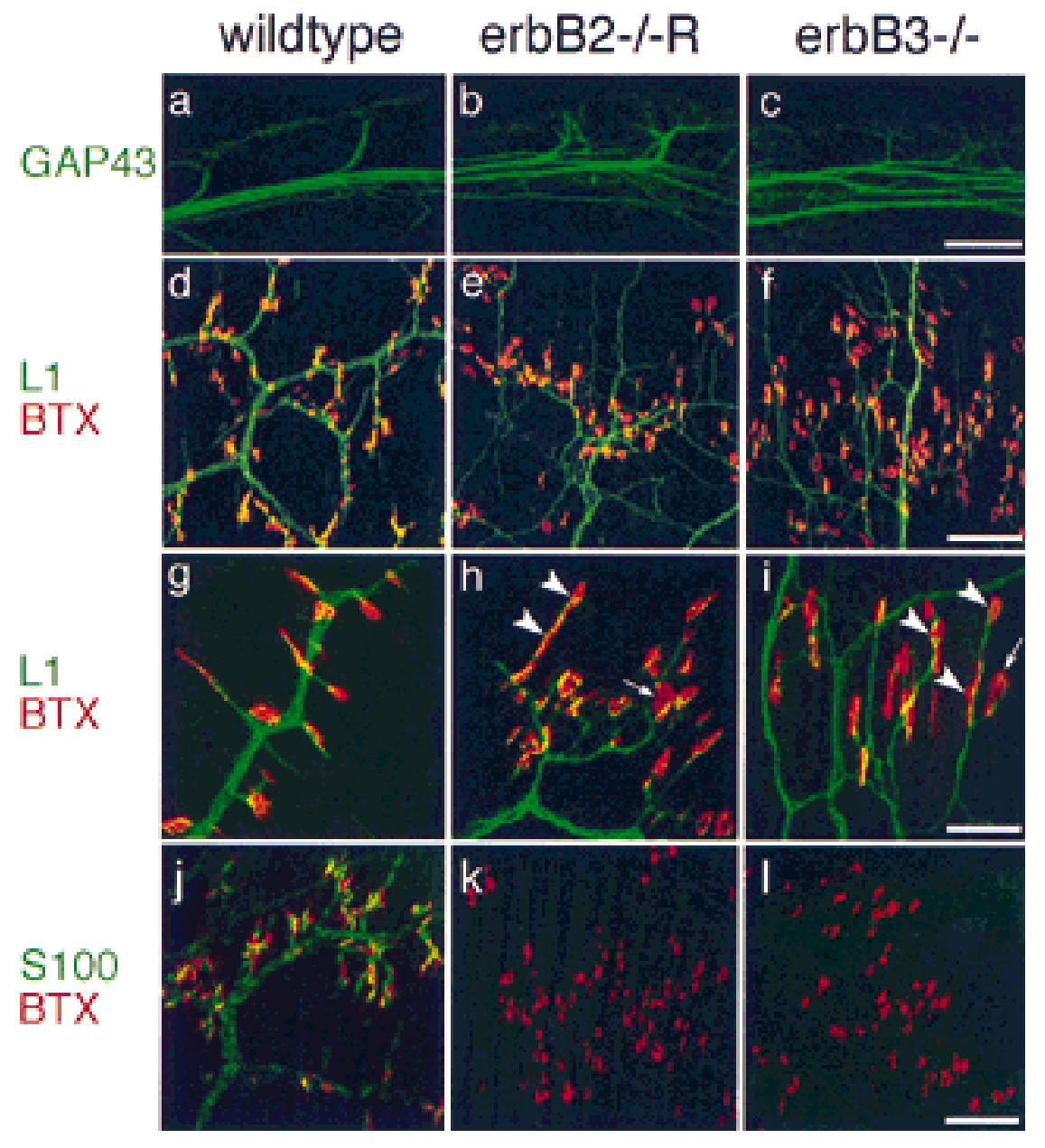

Figure 5. Absence of terminal Schwann cells, morphology of motor nerves, and distribution of neuromuscular synapses in rescued erbB2 mutants and in erbB3 mutants. $(a-c)$ Appearance of proximal nerve branches of 5 th intercostal nerves as visualized anti-GAP43 antibodies in wild-type embryos $(a)$, rescued erbB2 $(b)$, and in erbB3 $(c)$ mutants at E15.5. $(d-i)$ Distal projections of thoracic nerves (11th intercostal nerves) and associated synapses at E18.5 $(d-f)$ were visualized with anti-L1 antibodies (green) and rhodamine-labeled $\alpha$-bungarotoxin $($ red) in wild-type $(d)$, rescued erbB2 $(e)$, and erbB3 (f) mutant embryos. ( $g-i)$ High magnification of synapses associated with distal projections of thoracic nerves in control $(g)$, rescued erbB2 (h), and erbB3 (i) mutant embryos at E18.5; arrowheads point toward multiple synapses associated with one nerve branch, and arrows indicate large AChR clusters. (j-1) Schwann cells and terminal Schwann cells associated with distal projections of thoracic nerves (11th intercostal nerves) and their synapses in control $(j)$, in rescued erbB2 (k), and erbB3 (I) mutant embryos at E18.5. Anti-S100 antibodies (green) and labeled $\alpha$-bungarotoxin (red) were used to visualize Schwann cells and clustered AChR at the synapse. Bars $(a-c), 160 \mu \mathrm{m} ;(d-f, j-1)$ $100 \mu \mathrm{m} ;(g-i) 40 \mu \mathrm{m}$.
E15.5 in rescued erbB2 mutants and in erbB3 mutants, and were present not only in the center of diaphragm muscle, but also at its borders. Frequently, the nerve had apparently withdrawn from the AChR clusters (not shown).

We analyzed post-synaptically expressed genes in intercostal and diaphragm muscles at E18.5, that is, muscle innervated by motor nerves that derive from thoracic (intercostal) and from cervical (diaphragm) axial levels. In innervated muscle, expression of $\alpha-A C h R, R I$ -
$P K A$, and $A C h E$ is restricted to post-synaptic nuclei, and induction of $\epsilon-A C h R$ is observed when synapses mature (Witzemann et al. 1991; Imaizumi et al. 1996; Massoulie et al. 1998). In intercostal muscles, postsynaptic expression of $\alpha-A C h R, R I-P K A, A C h E$, and of low levels of $\epsilon-A C h R$ were observed in rescued erbB2 mutants, in erbB3 mutants, and in control animals (Fig. 7a-f; data not shown). Signal intensities appeared moderately reduced with $\alpha-A C h R, R I-P K A$, and $A C h E$ probes, and bands of expressing nuclei were broader. Occasionally, wildtype

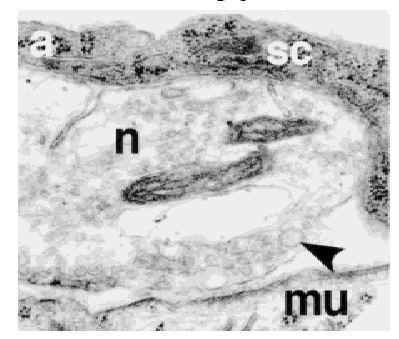

erbB2-/-R

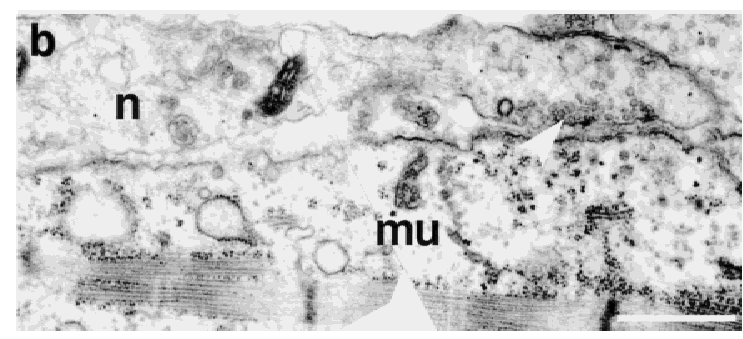

Figure 6. Ultrastructural analysis of neuromuscular synapses in rescued erbB2 mutants. Neuromuscular synapses in intercostal muscle of wild-type $(a)$ and rescued erbB2 mutant $(b)$ embryos at E15.5 are shown. In both photographs, nerve (n) is up and muscle $(\mathrm{mu})$ is down. The terminal Schwann cell (sc) that wraps the presynaptic motor nerve ending in the wild-type embryo has an electron-dense cytosol rich in ribosomes. The motor nerve endings inwild-type and mutant embryos accumulate synaptic vesicles (arrowheads). The synaptic region in the mutant (right end in $b$ ) exhibits synaptic extracellular matrix and postsynaptic electron dense material. Note the extended contact between nerve and muscle in the mutant. Bar, $0.7 \mu \mathrm{m}$. 
Figure 7. Postsynaptic gene expression in rescued erbB2 mutants. Whole-mount in situ hybridization on intercostal $(a-f)$ or diaphragm muscle $(g-l)$. The muscle tissue was derived from wild-type $(a, d, g, j)$, rescued $\operatorname{erbB2}(b, e, h, k)$, and erbB3 mutants $(c, f, i, l)$ at E18.5. The probes used were specific for RI-PKA $(a-c, g-i), \alpha$-AChR $(d-f)$, and $\epsilon$-AChR $(j-1)$. Arrowheads in $e$ and $f$ point toward muscle fibers that do not show restricted expression of $\alpha$-AChR. Arrowhead in $h$ points toward nuclei distant from the major branch of the phrenic nerve. Bars $(a-c), 400 \mu \mathrm{m}$; $(d-f, g-i) 200 \mu \mathrm{m}$; (j-l) $100 \mu \mathrm{m}$.

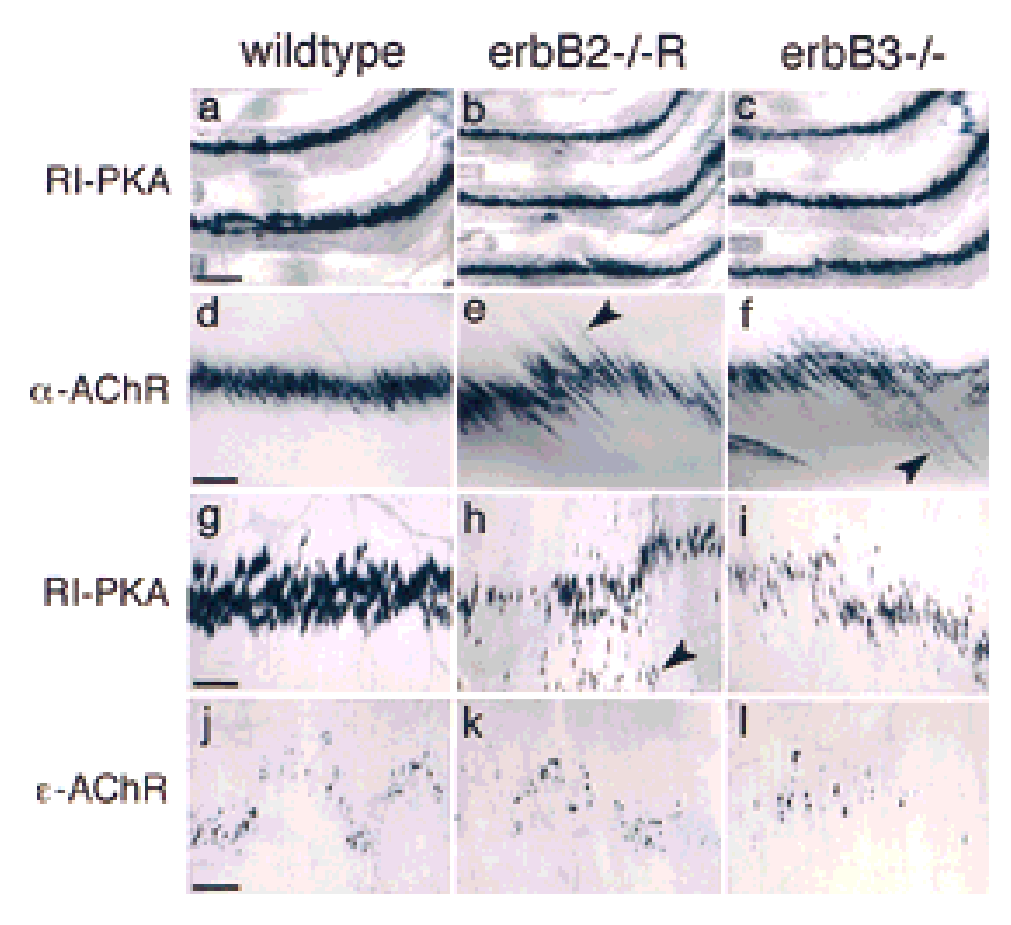

receptors (Goldman et al. 1990; Daub et al. 1996; Qiu et al. 1998). Despite many potential functions of ErbB2, rescued erbB2 mutants are remarkably similar to erbB3 mutants, indicating that the major physiological role of ErbB2 during development is to provide a coreceptor function for neuregulin receptors ErbB3 and ErbB4.

Loss of motoneuron subpopulations and of sensory neurons in rescued erbB2 mutants

A severe loss of motoneurons is observed in rescued erbB2 and erbB3 mutants in the cervical and lumbar spinal cord at E18.5, whereas thoracic motoneurons are minimally affected. Thus, cervical and lumbar motoneurons appear to differ from thoracic motoneurons in their requirement for, or their sensitivity toward, trophic factors that are absent in the mutants. It is well established that spinal motoneurons are heterogeneous and differ in expression of genes encoding transcription factors such as members of the Lim family (Tsuchida et al. 1994). Lim factors determine motoneuron identity, and subdivide motoneurons into different classes that take characteristic paths to their targets. Differentially expressed transcription factors could thus provide the molecular basis for distinct sensitivities toward trophic factors. For instance, motoneuron subpopulations express different levels of the c-met receptor tyrosine kinase, whose activity can affect motoneuron survival. SF/HGF, the ligand of c-Met, as well as a muscle-derived factor of unknown molecular structure (CDF, ChAT development factor) differentially promote survival of cultured motoneurons that derive from distinct axial levels (McManaman et al. 1990; Yamamoto et al. 1997). Selective loss of motoneuron subpopulations was not reported previously 
in mutant mice during development. However, degenerative motoneuron diseases in mice and man can primarily affect motoneurons on particular axial levels. This raises the intriguing possibility that related molecular mechanisms function in differential survival of motoneurons during development and in motoneuron diseases in the adult.

The proportion of motoneuron loss at different axial levels is similar in rescued erbB2 mutants and in erbB3 mutants. ErbB3 is not required in a cell autonomous manner for survival of sensory or motoneurons (Riethmacher et al. 1997). We suggest that erbB2 acts in a similar manner and affects motoneuron survival indirectly. Differentiating Schwann-cells or Schwann cell precursors might provide the trophic support missing in the mutants; trophic support could be provided by soluble factors or by direct contact between Schwann cells and axons. Schwann cells in vitro produce various neurotrophic factors that might affect motoneuron survival in vivo (Bunge 1993). Alternatively, ErbB2 and ErbB3 expressed in skeletal muscle could regulate the expression of motoneuron survival factors. Cell type-specific ablation of erbB2 in Schwann-cell precursors or skeletal muscle will allow the determination of the source of the neurotrophic factor(s) in the future. In rescued erbB2 or in erbB3 mutants, abnormal loss of motoneurons occurs after E15.5 in the lumbar spinal cord. Naturally occurring motoneuron loss or abnormal motoneuron loss induced by experimental ablation of skeletal muscle occurs between E13.5 and birth on lumbar axial levels, and thus in an overlapping, but not identical time frame (Grieshammer et al. 1998).

\section{Development of Schwann cells and sensory nerves in rescued erbB2 mutant mice}

Schwann cells accompany sensory and motoneurons and derive from the neural crest (Le Douarin 1982). In erbB2 null mutant mice, the number of Schwann-cell precursors is already severely reduced at E10.5 (S. Britsch and C. Birchmeier, unpubl.). At early stages, reduced numbers of Sox10-positive or $\mathrm{P}_{0}$-positive cells are detected in portions of sensory and motor nerves close to the spinal cord, but are absent in the periphery, for instance, along phrenic or intercostal nerves of rescued erbB2 mutants. Thus, the few precursor cells present do not expand, nor do they migrate along the axons. However, a cellular layer that surrounds nerve bundles is apparent. These cells express neither marker (Sox10 or $\mathrm{P}_{0}$ ) typical for Schwann cells, Schwann-cell precursors or neural crest cells, nor do they express a marker for the perineurium (patched; S. Britsch and C. Birchmeier, unpubl.). Patched encodes a hedgehog receptor and is expressed in the embryonal perineurium, whose development is in part controlled by desert hedgehog produced by Schwann cells (Parmantier et al. 1999). The observed cellular layer might therefore correspond to an abnormal perineurium. Alternatively, it might originate from neural crest cells that ceased to express genes typical for the lineage. The absence of Schwann cells in rescued erbB2 mutant em- bryos may contribute to the abnormal morphology of nerves, and our results are compatible with a functional role of Schwann cells in organization and bundling of peripheral nerves.

Despite the disorganization and severe defasciculation of sensory nerves, the general trajectory appears similar in control and rescued erbB2 mutants. However, we observe a severe loss of sensory neurons that starts after E12.5 on lumbar axial levels. In contrast to the loss of motoneurons, sensory neuron loss is not restricted to particular axial levels, but is pronounced in all dorsal root ganglia at E18. At earlier stages, cranio-caudal gradients in the extent of degeneration are apparent. Time course and extent of degeneration of sensory neurons are similar in rescued erbB2 and erbB3 mutants. We have demonstrated previously that $e r b B 3$ is not required in a cell-autonomous manner for survival of sensory neurons. We suggest that erbB2 acts in a similar manner and affects the survival of sensory neurons indirectly.

\section{Neuromuscular synapse formation and postsynaptic gene expression in rescued erbB2 mutants}

Genetic analysis in mice has provided new insights into the molecular control of neuromuscular synaptogenesis (Sanes and Lichtman 1999). Neuronal agrin initiates synaptogenesis, and ablation of the agrin gene results in incomplete AChR clustering and lack of postsynaptic specialization (McMahan 1990; Gautam et al. 1996). MuSK, a muscle-specific tyrosine kinase receptor, might function in the recognition of agrin, because $\mathrm{MuSK}^{-/-}$mice do not form synapses. However, MuSK does not bind agrin directly (DeChiara et al. 1996; Glass et al. 1996). Rapsyn, a downstream cytoplasmic component, is essential for clustering of AChR and ErbB2 as well as for postsynaptic specialization (Gautam et al. 1995; Moscoso et al. 1995). Despite a lack of, or a severe impairment in formation of synapses, loss of motoneurons was not reported in such mutant mice. Thus, synapse formation appears not to be essential for motoneuron survival if axons reach their targets. Synapse formation is not sufficient for motoneuron survival in rescued erbB2 and in erbB3 mutants, as pronounced motoneuron loss is detected although synapses form.

Neuregulin induces $A C h R$ expression in cultured muscle cells, and it was postulated to induce postsynaptic expression of the $A C h R$ subunit genes (Missias et al. 1996; Fischbach and Rosen 1997; Fromm and Burden 1998; Rimer et al. 1998; Schaeffer et al. 1998). In accordance with an important role in neuromuscular junctions, neuregulin-1 and the ErbB2, ErbB3, and ErbB4 receptors are clustered at the synapses (Altiok et al. 1995; Jo et al. 1995; Zhu et al. 1995). Changes in endplate potential were reported in mice heterozygous for a neuregulin-1 mutation (NRG $G^{I G}$ allele), indicating a rate-limiting function of the factor in maintaining high AChR concentrations at the endplate (Sandrock et al. 1997). We analyzed synapse formation in rescued erbB2 and in erbB3 mutant embryos. Despite a general disorganization of phrenic and intercostal nerves, AChR clustering 
and postsynaptic expression of $\alpha-A C h R, R I-P K A, A C h E$, and $\epsilon-A C h R$ can occur. Moreover, ultrastructural specialization such as synaptic vesicle accumulations, active zones, and postsynaptic densities were observed. Thus, synaptogenesis is initiated, and the first steps of synaptic maturation occur. Synapses that formed in the rescued erbB2 and in erbB3 mutants appear at least partially functional, because mutant embryos move at E16.5, albeit less than control animals. At birth, spontaneous motion is not observed, although prolonged tactile stimulation can occasionally result in trunk, but not in limb movement. Skeletal muscle expresses erbB2, $\operatorname{erbB3}$, and erbB4, but only one of these receptors is lacking in our mutants; the remaining receptors might thus function in a redundant manner in the control of postsynaptic gene expression. We did, however, detect ectopic AChR clusters and nerve sprouting in the mutant mice and broadening of bands of nuclei that express these genes. This may reflect a failure of effective synapse maturation due to impaired neuregulin signaling at the synapse. However, the absence of terminal Schwann cells might also contribute to these changes. Quantitative changes in postsynaptic gene expression are pronounced in the diaphragm but not in intercostal muscle, which appears to reflect the early withdrawal of the phrenic nerve rather than a genuine difference in the control of postsynaptic gene expression.

Terminal Schwann cells cap the neuromuscular junction and modulate synaptic transmission, affect regeneration of synapses in paralyzed or partially denervated muscle, and have been implicated in the maintenance of the neuromuscular synapse (Balice 1996; Son et al. 1996; Ullian and Barres 1998). Here, we demonstrate that synapses are formed and are stable over several days during intrauterine development in the absence of terminal Schwann cells. However, their absence may contribute to alterations in morphology of synapses, nerves, and nerve sprouting that are observed in rescued erbB2 and in erbB3 mutants.

\section{Materials and methods}

\section{Construction and expression of the $\mathrm{Nkx} 2.5^{\mathrm{erbB} 2}$ allele}

The structure of the Nkx2.5 gene has been described (Lyons et al. 1995). To generate the Nkx2.5 $5^{\text {erbB2 }}$ allele, a targeting vector was constructed that fuses rat erbB2 cDNA (Bargmann et al. 1986) to the start codon of Nkx2.5 in exon 1. The inserted fragment contains, in addition, SV40 splice donor and acceptor sites, as well as a poly(A) addition sequence that derives from the pSV2neo plasmid (Bargmann et al. 1986). For selection of ES cells, the targeting vector also contained neomycin resistance cassette $(n e o)$ and the thymidine kinase $(t k)$ gene. Gene targeting in ES cells and the generation of mice that carry the Nkx2. $5^{\text {erbB2 }}$ allele was performed as described (Meyer and Birchmeier 1995). Routine genotyping was performed by PCR. Rat erbB2 transcripts that derive from the Nkx2. $5^{\text {erbB2 }}$ allele were identified by RT-PCR. RNA from different tissues was isolated by the use of TRIzol and a RT-PCR kit (GIBCO-BRL). Primers used for the amplification hybridize to the 3 '-nontranslated sequence and are located upstream and downstream of the SV40 splice site present in the transcript (Bargmann et al. 1986).
In situ hybridization, histology, immunohistochemistry, and microscopy

Whole-mount in situ hybridization was performed as described (Britsch et al. 1998). To allow better access of hybridization solutions, mouse embryos at E12.5 were cut into halves and, from E15.5 and E18.5 embryos, rib cages and attached muscles of the thorax (intercostal, diaphragm muscles, and some associated muscles of the abdominal wall) were dissected prior to hybridization.

For histological analysis, mouse embryos or tissues were fixed in $4 \%$ PFA for several days at $4{ }^{\circ} \mathrm{C}$, dehydrated, and embedded in Technovit 7100 (Kulzer); 4- to 6- $\mu \mathrm{m}$ sections were stained with hematoxylin/eosin or with toluidine blue. For electron microscopy, embryos were fixed in glutaraldehyde and embedded in Durcupan. Ultrathin sections were then cut, contrasted with lead citrate, and viewed on a Zeiss EM910 electron microscope.

For immunohistological analysis, the embryos were prefixed, the diaphragms or thoracic walls were dissected, postfixed in $4 \%$ PFA, blocked with $20 \%$ goat serum (GS) in PBT (PBS/0.1\% Tween-20), and incubated with anti-GAP43, anti-L1, anti-S100 polyclonal (Daco) antibodies, or rhodamine-labeled $\alpha$-bungarotoxin in PBT containing $5 \%$ goat serum at $4^{\circ} \mathrm{C}$ overnight. Cy2-conjugated anti-rabbit IgG (1:300; Dianova) was used as secondary antibody. The samples were examined with a Leica confocal microscope. Whole-mount immunhistochemistry on E12.5 embryos was performed on embryos that were cut into halves with polyclonal rabbit anti-L1 antibodies and peroxidasecoupled goat anti-rabbit antibodies. Embryos were cleared in benzyl alcohol/benzyl benzoate (1:2).

\section{Motoneuron and sensory neuron counts}

Embryos were prefixed in PFA, and appropriate segments of the spinal cord were dissected, with the attached dorsal root ganglia as reference points to determine the axial level. After postfixation, dorsal root ganglia were removed to improve access of the hybridization solutions, and whole-mount in situ hybridization with a VAChT-specific probe was performed. The stained tissue was embedded in plastic and cut into 6- $\mu \mathrm{m}$ sections. Every third section was examined, the numbers of nuclei located in the ventral horn that were surrounded by blue-stained cytoplasm were counted, and the averages of nuclei per section were determined. For each animal, the average numbers of motoneurons were determined on different axial levels. The data displayed are mean numbers of the averages of several animals.

Embryos or segments containing L4 and L5 dorsal root ganglia were embedded in Technovit 7100 (Kulzer). Serial sections $(6 \mu \mathrm{m})$ through L4 and L5 dorsal ganglia were stained with toluidine blue and every third section was counted. In ganglia of E14.5, E16.5, and E18.5 embryos, cells with a clear nucleus and nucleoli were counted; in ganglia from E12.5 embryos, total cell numbers were determined. Counts were not corrected for double or split nucleoli.

\section{Acknowledgments}

We thank D. Wolpwitz (New York) for advice on counting of motoneurons, K. Jessen (London) for information on unpublished data and for pointing out patched as a marker for the perineurium, S. Burden (New York) and H.-R. Brenner (Basel) for helpful discussions, Y. Yamaai for help with the anatomical analysis of the mutants, and F. Rathjen (Berlin) for a gift of anti-L1 antibodies. We also thank the following scientists who have provided plasmids used in this study: Sox10, M. Wegner (Hamburg); RI subunit of PKA, M. Weiss (Paris) and S. McKnight 
(Seattle); AChE, C. Legay (Paris); patched, M. Scott (Stanford); VAChT, J. Dedman (Cincinnati) and D. Wolpowitz (New York); $\alpha$-AChR and $\epsilon$-AChR, V. Witzemann (Heidelberg). We are grateful to A. Rehaus, K. Gottschling, and S. Buchert for expert technical assistance, M. Strehle for help with preparation of Figure 1, as well as W. Birchmeier, A. Garratt, G. Mashour, and F. Rathjen for critical reading of the manuscript. This work was supported by grants from GIF, DFG, and BMBF to C.B.

The publication costs of this article were defrayed in part by payment of page charges. This article must therefore be hereby marked 'advertisement' in accordance with 18 USC section 1734 solely to indicate this fact.

\section{References}

Altiok, N., J.L. Bessereauand, and J.P. Changeux. 1995. ErbB3 and ErbB2/neu mediate the effect of heregulin on acetylcholine receptor gene expression in muscle: Differential expression at the endplate. $E M B O J$. 14: 4258-4266.

Balice, G.R. 1996. Dynamic roles at the neuromuscular junction. Schwann cells. Curr. Biol. 6: 1054-1056.

Bargmann, C.I., M.C. Hung, and R.A. Weinberg. 1986. Multiple independent activations of the neu oncogene by a point mutation altering the transmembrane domain of p185. Cell 45: 649-657.

Britsch, S., L. Li, S. Kirchhoff, F. Theuring, V. Brinkmann, C. Birchmeier, and D. Riethmacher. 1998. The ErbB2 and ErbB3 receptors and their ligand, neuregulin-1, are essential for development of the sympathetic nervous system. Genes \& Dev. 12: 1825-1836.

Bunge, R.P. 1993. Expanding roles for the Schwann cell: Ensheathment, myelination, trophism and regeneration. Curr. Opin. Neurobiol. 3: 805-809.

Burden, S. and Y. Yarden. 1997. Neuregulins and their receptors: A versatile signaling module in organogenesis and oncogenesis. Neuron 18: 847-855.

Carraway, K. III and L.C. Cantley. 1994. A neu acquaintance for erbB3 and erbB4: A role for receptor heterodimerization in growth signaling. Cell 78: 5-8.

Daub, H., F.U. Weiss, C. Wallasch, and A. Ullrich. 1996. Role of transactivation of the EGF receptor in signalling by G-protein-coupled receptors. Nature 379: 557-560.

DeChiara, T.M., D.C. Bowen, D.M. Valenzuela, M.V. Simmons, W.T. Poueymirou, S. Thomas, E. Kinetz, D.L. Compton, E. Rojas, J.S. Park, et al. 1996. The receptor tyrosine kinase MuSK is required for neuromuscular junction formation in vivo. Cell 85: 501-512.

Erickson, S.L., K.S. O'Shea, N. Ghaboosin, L. Loverro, G. Frantz, M. Bauer, L.H. Lu, and M.W. Moore. 1997. ErbB3 is required for normal cerebellar and cardiac development: A comparison with erbB2 and heregulin deficient mice. Development 124: 4999-5011.

Falls, D.L., K.M. Rosen, G. Corfas, W.S. Lane, and G.D. Fischbach. 1993. ARIA, a protein that stimulates acetylcholine receptor synthesis, is a member of the neu ligand family. Cell 72: 801-815.

Fischbach, G.D. and K.M. Rosen. 1997. ARIA: A neuromuscular junction neuregulin. Annu. Rev. Neurosci. 20: 429-458.

Fromm, L. and S.J. Burden. 1998. Synapse-specific and neuregulin-induced transcription require an ets site that binds GABP $\alpha /$ GABP $\beta$. Genes \& Dev. 12: 3074-3083.

Gassmann, M., F. Casagranda, D. Orioli, H. Simon, C. Lai, R. Klein, and G. Lemke. 1995. Aberrant neural and cardiac development in mice lacking the erbB4 neuregulin receptor. Nature 378: 390-394.
Gautam, M., P.G. Noakes, J. Mudd, M. Nichol, G.C. Chu, J.R Sanes, and J.P. Merlie. 1995. Failure of postsynaptic specialization to develop at neuromuscular junctions of rapsyn-deficient mice. Nature 377: 232-236.

Gautam, M., P.G. Noakes, L. Moscoso, F. Rupp, R.H. Scheller, J.P. Merlie, and J.R. Sanes. 1996. Defective neuromuscular synaptogenesis in agrin-deficient mutant mice. Cell 85: 525535.

Glass, D.J., D.C. Bowen, T.N. Stitt, C. Radziejewski, J. Bruno, T.E. Ryan, D.R. Gies, S. Shah, K. Mattsson, S.J. Burden, P.S. DiStefano, D.M. Valenzuela, T.M. DeChiara, and G.D. Yancopoulos. 1996. Agrin acts via a MuSK receptor complex. Cell 85: 513-523.

Goldman, R., R.B. Levy, E. Peles, and Y. Yarden. 1990. Heterodimerization of the erbB-1 and erbB-2 receptors in human breast carcinoma cells: A mechanism for receptor transregulation. Biochemistry 29: 11024-11028.

Grieshammer, U., M. Lewandoski, D. Prevette, R.W. Oppenheim, and G.R. Martin. 1998. Muscle-specific cell ablation conditional upon Cre-mediated DNA recombination in transgenic mice leads to massive spinal and cranial motoneuron loss. Dev. Biol. 197: 234-247.

Holmes, W.E., M.X. Sliwkowski, R.W. Akita, W.J. Henzel, J. Lee, J.W. Park, D. Yansura, N. Abadi, H. Raab, G.D. Lewis, et al. 1992. Identification of heregulin, a specific activator of p185erbB2. Science 256: 1205-1210.

Imaizumi, S.T., D.M. Faust, J.C. Benichou, R. Hellio, and M.C. Weiss. 1996. Accumulation in fetal muscle and localization to the neuromuscular junction of cAMP-dependent protein kinase A regulatory and catalytic subunits RI alpha and C alpha. J. Cell Biol. 134: 1241-1254.

Jo, S.A., X. Zhu, M.A. Marchionni, and S.J. Burden. 1995. Neuregulins are concentrated at nerve-muscle synapses and activate ACh-receptor gene expression. Nature 373: 158-161.

Kraus, M.H., W. Issing, T. Miki, N.C. Popescu, and S.A. Aaronson. 1989. Isolation and characterization of ERBB3, a third member of the ERBB/epidermal growth factor receptor family: Evidence for overexpression in a subset of human mammary tumors. Proc. Natl. Acad. Sci. 86: 9193-9197.

Le Douarin, N.M. 1982. The neural crest. Cambridge University Press, Cambridge, UK.

Lee, K.F., H. Simon, H. Chen, B. Bates, M.C. Hung, and C. Hauser. 1995. Requirement for neuregulin receptor erbB2 in neural and cardiac development. Nature 378: 394-398.

Lenferink, A.E., R. Pinkas-Kramarski, H.L. van de Poll, M.J. van Vugt, L.N. Klapper, E. Tzahar, H. Waterman, M. Sela, and Y. Yarden. 1998. Differential endocytic routing of homo- and hetero-dimeric ErbB tyrosine kinases confers signaling superiority to receptor heterodimers. EMBO J. 17: 3385-3397.

Lints, T.J., L.M. Parsons, L. Hartley, I. Lyons, and R.P. Harvey. 1993. Nkx-2.5: A novel murine homeobox gene expressed in early heart progenitor cells and their myogenic descendants. Development 119:

Lyons, I., L.M. Parsons, L. Hartley, R. Li, J.E. Andrews, L. Robb, and R.P. Harvey. 1995. Myogenic and morphogenetic defects in the heart tubes of murine embryos lacking the homeo box gene Nkx2-5. Genes \& Dev. 9: 1654-1666.

Marchionni, M.A., A.D. Goodearl, M.S. Chen, M.O. Bermingham, C. Kirk, M. Hendricks, F. Danehy, D. Misumi, J. Sudhalter, K. Kobayashi et al. 1993. Glial growth factors are alternatively spliced erbB2 ligands expressed in the nervous system. Nature 362: 312-318.

Massoulie, J., A. Anselmet, S. Bon, E. Krejci, C. Legay, N. Morel, and S. Simon. 1998. Acetylcholinesterase: C-terminal domains, molecular forms and functional localization. J. Physiol. Paris 92: 183-190. 
McMahan, U.J. 1990. The agrin hypothesis. Cold Spring Harbor Symp. Quant. Biol. 55: 407-418.

McManaman, J.L., R.W. Oppenheim, D. Prevette, and D. Marchetti. 1990. Rescue of motoneurons from cell death by a purified skeletal muscle polypeptide: Effects of the ChAT development factor, CDF. Neuron 4: 891-898.

Meyer, D. and C. Birchmeier. 1995. Multiple essential functions of neuregulin in development. Nature 378: 386-390.

Missias, A.C., G.C. Chu, B.J. Klocke, J.R. Sanes, and J.P. Merlie. 1996. Maturation of the acetylcholine receptor in skeletal muscle: Regulation of the AChR gamma-to-epsilon switch. Dev. Biol. 179: 223-238.

Moscoso, L.M., G.C. Chu, M. Gautam, P.G. Noakes, J.P. Merlie, and J.R. Sanes. 1995. Synapse-associated expression of an acetylcholine receptor-inducing protein, ARIA/heregulin, and its putative receptors, ErbB2 and ErbB3, in developing mammalian muscle. Dev. Biol. 172: 158-169.

Naciff, J.M., H. Misawa, and J.R. Dedman. 1997. Molecular characterization of the mouse vesicular acetylcholine transporter gene. Neuroreport 8: 3467-3473.

Parmantier, E., B. Lynn, D. Lawson, M. Turmaine, S.S. Namini, L. Chakrabarti, A. McMahon, K. Jessen, and R. Mirsky. 1999. Schwann cell-derived desert hedghog controls the development of peripheral nerve sheaths. Neuron 23: 1-20.

Pinkas, K.R., M. Shelly, B.C. Guarino, L.M. Wang, L. Lyass, I. Alroy, M. Alamandi, A. Kuo, J.D. Moyer, S. Lavi, et al. 1998. ErbB tyrosine kinases and the two neuregulin families constitute a ligand-receptor network. Mol. Cell. Biol. 18: 60906101.

Plowman, G.D., G.S. Whitney, M.G. Neubauer, J.M. Green, V.L. McDonald, G.J. Todaro, and M. Shoyab. 1990. Molecular cloning and expression of an additional epidermal growth factor receptor-related gene. Proc. Natl. Acad. Sci. 87: 49054909.

Qiu, Y., L. Ravi, and H.J. Kung. 1998. Requirement of ErbB2 for signalling by interleukin- 6 in prostate carcinoma cells. $\mathrm{Na}$ ture 393: 83-85.

Riese, D.J. and D.F. Stern. 1998. Specificity within the EGF family/ErbB receptor family signaling network. BioEssays 20: $41-48$.

Riethmacher, D., R.E. Sonnenberg, V. Brinkmann, T. Yamaai, G.R. Lewin, and C. Birchmeier. 1997. Severe neuropathies in mice with targeted mutations in the ErbB3 receptor. Nature 389: 725-730.

Rimer, M., I. Cohen, T. Lomo, S.J. Burden, and U.J. McMahan. 1998. Neuregulins and erbB receptors at neuromuscular junctions and at agrin-induced postsynaptic-like apparatus in skeletal muscle. Mol. Cell. Neurosci. 12: 1-15.

Sandrock, A.W., S.E. Dryer, K.M. Rosen, S.N. Gozani, R. Kramer, L.E. Theill, and G.D. Fischbach. 1997. Maintenance of acetylcholine receptor number by neuregulins at the neuromuscular junction in vivo. Science 276: 599-603.

Sanes, J.R. and J.W. Lichtman. 1999. Development of the vertebrate neuromuscular junction. Annu. Rev. Neurosci. 22: 389-442.

Schaeffer, L., N. Duclert, D.M. Huchet, and J.P. Changeux. 1998. Implication of a multisubunit Ets-related transcription factor in synaptic expression of the nicotinic acetylcholine receptor. EMBO J. 17: 3078-3090.

Son, Y.J., J.T. Trachtenberg, and W.J. Thompson. 1996. Schwann cells induce and guide sprouting and reinnervation of neuromuscular junctions. Trends Neurosci. 19: 280-285.

Tsuchida, T., M. Ensini, S.B. Morton, M. Baldassare, T. Edlund, T.M. Jessell, and S.L. Pfaff. 1994. Topographic organization of embryonic motor neurons defined by expression of LIM homeobox genes. Cell 79: 957-970.
Tzahar, E. and Y. Yarden. 1998. The ErbB-2/HER2 oncogenic receptor of adenocarcinomas: From orphanhood to multiple stromal ligands. Biochim. Biophys. Acta. 1377: M25-M37.

Ullian, E.M. and B.A. Barres. 1998. The Schwann song of the glia-less synapse. Neuron 21: 651-652.

Weiss, F.U., H. Daub, and A. Ullrich. 1997. Novel mechanisms of RTK signal generation. Curr. Opin. Genet. Dev. 7: 80-86.

Wen, D., E. Peles, R. Cupples, S.V. Suggs, S.S. Bacus, Y. Luo, G. Trail, S. Hu, S.M. Silbiger, R.B. Levy et al. 1992. Neu differentiation factor: A transmembrane glycoprotein containing an EGF domain and an immunoglobulin homology unit. Cell 69: $559-572$.

Witzemann, V., H.R. Brenner, and B. Sakmann. 1991. Neural factors regulate $\mathrm{AChR}$ subunit mRNAs at rat neuromuscular synapses. J. Cell Biol. 114: 125-141.

Yamamoto, Y., J. Livet, R.A. Pollock, A. Garces, V. Arce, O. deLapeyriere, and C.E. Henderson. 1997. Hepatocyte growth factor (HGF/SF) is a muscle-derived survival factor for a subpopulation of embryonic motoneurons. Development 124: 2903-2913.

Zhu, X., C. Lai, S. Thomas, and S.J. Burden. 1995. Neuregulin receptors, erbB3 and erbB4, are localized at neuromuscular synapses. EMBO I. 14: 5842-5848. 


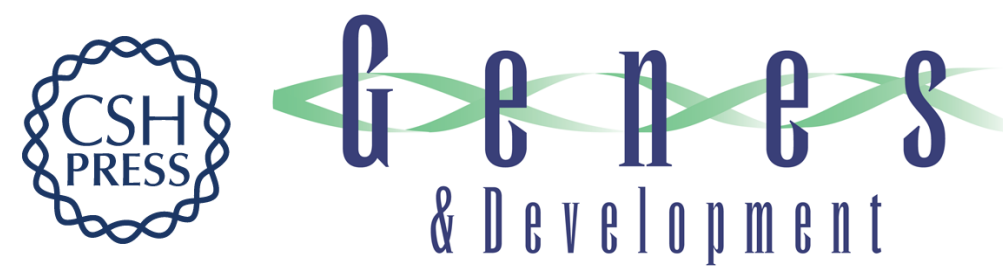

\section{Peripheral nervous system defects in erbB2 mutants following genetic rescue of heart development}

Masresha T. Woldeyesus, Stefan Britsch, Dieter Riethmacher, et al.

Genes Dev. 1999, 13:

References This article cites 53 articles, 15 of which can be accessed free at:

http://genesdev.cshlp.org/content/13/19/2538.full.html\#ref-list-1

License

Email Alerting

Receive free email alerts when new articles cite this article - sign up in the box at the top

Service

right corner of the article or click here.

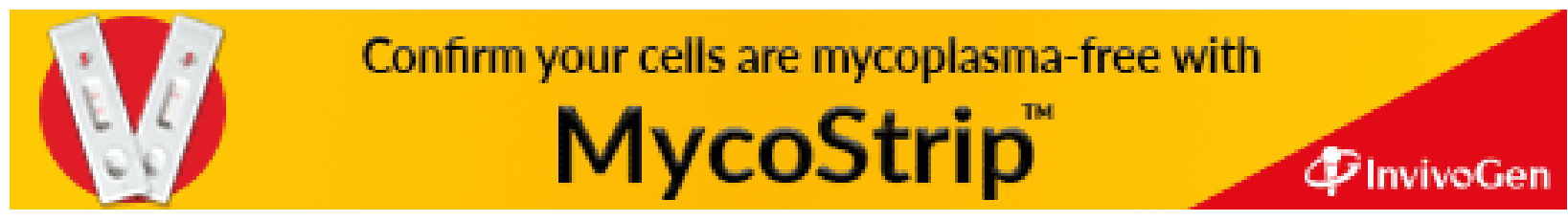

